\title{
Hazardous Situations and Accidents Caused by Light and Medium Unmanned Free Balloon Flights
}

\author{
N. Hegyi ${ }^{1, *}$, J. Jósvai ${ }^{1}$ \\ ${ }^{1}$ Széchenyi István University, Department of Vehicle Manufacturing \\ Egyetem tér 1, H-9026 Győr, Hungary \\ "E-mail: hegyi.norbert@ sze.hu
}

Abstract: The article deals with the presentation and analysis of hazardous situations, damage events and accidents caused by light and medium unmanned free balloons and the parts of them. During the flights of these balloons, emergencies, hazardous situations, and accidents can occur in many different ways. Hazardous situations and damages at the process of landing and after it have also many different variations. At the end of the article we draw conclusions based on the previous analyzes.

Keywords: unmanned free balloon; hazardous situation; damage; accident; tracking; structure

\section{Introduction}

The article shows the research on the hazardous situations and accidents caused by light and medium unmanned free balloon flights. Firstly, this type of balloons is shortly introduced. Then, in later chapters, the research explores the details.

\subsection{Light and medium unmanned free balloons}

Dangerous aircraft proximity or even aircraft collision are possible events during a light or medium unmanned free balloon flight. Emergencies can occur in different ways. It needs to be mentioned, that sounding balloons (also called weather balloons) are mostly light or medium unmanned free balloons also. [1]

As mentioned in other articles by N. Hegyi [2] [3] these balloons are assembled usually with 3 main parts: the balloon, the parachute, and the payload. Parachute is not installed on some versions, as shown on Fig. 1. 


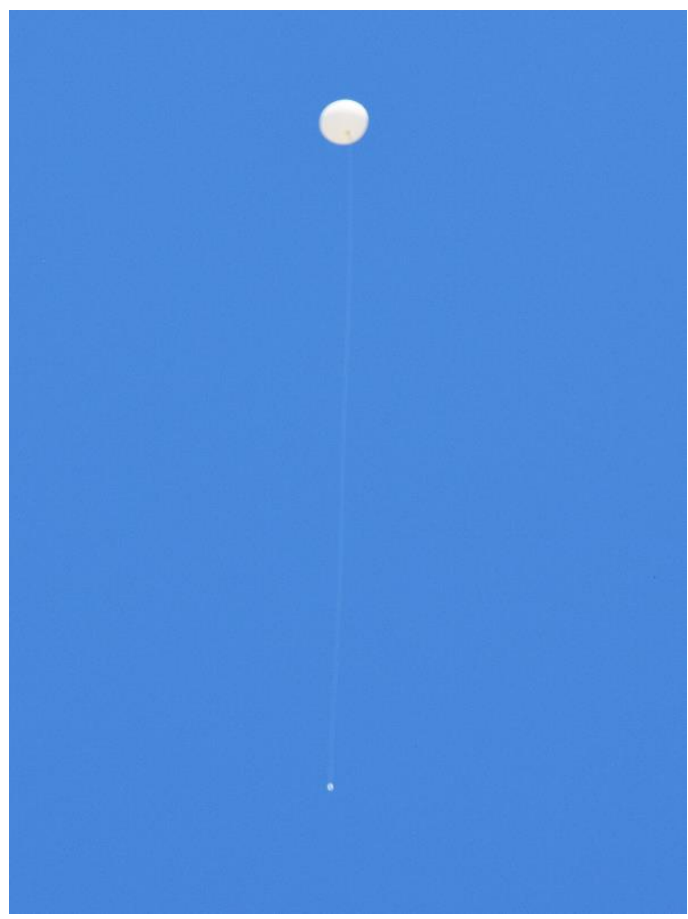

Figure 1. A sounding balloon after liftoff

It needs to be mentioned that light and medium unmanned free balloons are not visible by surveillance radars of HungaroControl (Hungarian Air Traffic Service) so dangerous aircraft proximity or near collision situations can occur.

\section{Aircraft proximity and accident events of light and medium unmanned free balloons}

Dangerous aircraft proximity or even collision are possible in the case of these balloons.

\subsection{Aircraft proximity and near collisions}

Two interviews with pilots have been made for obtaining data on visual detection of meteorological balloons during flight.

A jet airplane pilot has seen a white colored sounding balloon above the middle parts of Germany by daylight at morning hours in first half of May 2019. The 
weather was clear with a good visibility. His airplane flew at an altitude of 9-11 km with about a speed of $600 \mathrm{~km} / \mathrm{h}$. The balloon was on the left side of the airplane and it was very close. The distance between the airplane and the balloon was about 250$1000 \mathrm{~m}$ according to the pilot. As there is no reference point to determine the exact distance, the pilot also stated that the apparent size of the balloon was about that of the Moon or maybe smaller. The apparent diameter of the Moon is about 30 arcminutes on the sky. So, calculating with the 15'-30' apparent diameter and assuming a $600 \mathrm{~g}$ balloon filled with $1.6 \mathrm{~m}^{3}$ helium used by the German Meteorological Service (German: Deutscher Wetterdienst, DWD) may have had a volume about 4-5 $\mathrm{m}^{3}$ and a diameter about $2 \mathrm{~m}$ at that altitude. The calculated distance - if the apparent diameter was Moon size or a little smaller - had to be 230$500 \mathrm{~m}$ from the cockpit at the closest approach. The stated distance by the pilot could have been right. Just for a clear complete image if the apparent size was just a little bigger than the Moon (about 40'), then this distance was about $170 \mathrm{~m}$.

A copilot - an aviation instructor - of a motor glider saw a white colored sounding balloon near Szatymaz Airport in Hungary by daylight at morning hours in first days of May 2017. By his words the weather was CAVOK (an acronym meaning that ceiling and visibility are $\mathrm{OK}$ ). His airplane flew at 500-750m height above ground level with about a speed of $90 \mathrm{~km} / \mathrm{h}$. The copilot saw the balloon from about 1-2.5 $\mathrm{km}$ distance almost in front of the aircraft a little above horizon. Maybe 10 degrees above it. This distance is more exactly than it was stated in the jet pilot's interview. The airplane flew for a few minutes almost exactly in the direction of the balloon launch site in Szeged. The copilot stated that the weather balloon was not far but ascending and drifting sideways from the launch site. Most probably the sounding balloon had been launched 1-2 minutes earlier, as their ascent rate is commonly 4-6 $\mathrm{m} / \mathrm{s}(240-360 \mathrm{~m} / \mathrm{min})$ from this launch site.

N. Hegyi has already seen a sounding balloon during a jet flight as a passenger in 1992 above Northern-Italy announced by the flight crew. Unfortunately, he does not remember any precise information about the incident. This event is mentioned in order to raise awareness, that any passenger may encounter meteorological balloons near an airplane.

As seen in the three cases the visual detection of meteorological balloons is possible. By the comparison of the first and second interview it can be concluded, that at high speeds with a jet airplane a visual detection of a sounding balloon will occur at a shorter distance than at relatively slower speeds. With just two presented interviews it may seem, that this is not a stable confirmation, but by looking on other factors it can be supported in several ways. For example, a commercial jet's cockpit has mostly a smaller field of view compared to a motor glider. Or by calculating the route in front of an aircraft a jet airplane with $600 \mathrm{~km} / \mathrm{h}$ would travel a distance of 
$2.5 \mathrm{~km}$ in 15 seconds. A motor glider with $90 \mathrm{~km} / \mathrm{h}$ would travel the same distance in about 100 second, i.e. 1 minute 40 seconds. If the calculation is reduced to the detection distance of the jet airplane's case which is $1 \mathrm{~km}$, this would reduce the flight time to 6 seconds for the jet and 40 seconds for the motor glider. A sounding balloon with an ascent rate of $5 \mathrm{~m} / \mathrm{s}$ climbs 30 meters higher in 6 seconds or 200 meters in 40 seconds. This could lead to a dangerous proximity or even a collision in case of a commercial jet airplane, but a motor glider would approach slow enough to avoid dangerous situations.

\subsection{Meteorological balloon's collision with an airplane}

A meteorological balloon's parts can cause accidents as a whole or also separately. On 16th September 1970, a MiG-19PM supersonic fighter jet collided with a meteorological balloon. The pilot catapulted, surviving the accident. The aircraft crashed into ground at a village named Szágy in Hungary. On Fig. 2. the damaged parts of the aircraft are shown. [4]

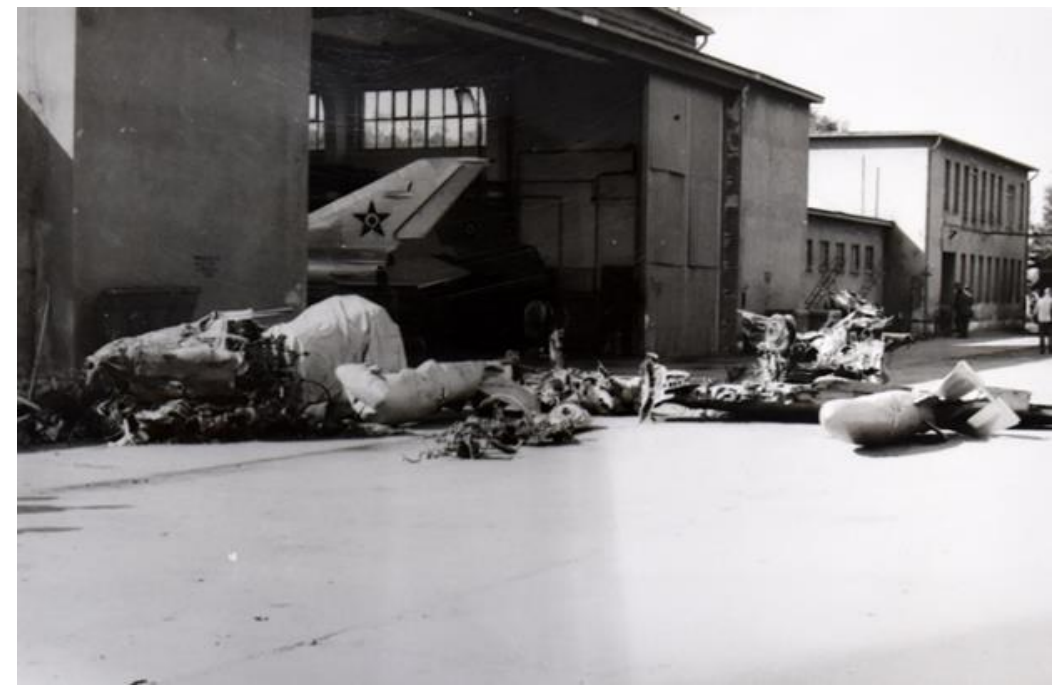

Figure 2. The collected parts of the airplane [4]

At the moments of the collision the fighter flew at an altitude of 4,000 meters with a ground speed of $930-950 \mathrm{~km} / \mathrm{h}$. According to the results of the Hungarian People's Army's aircraft accident investigation report, the aircraft collided with a meteorological balloon. The radiosonde has been found 2125 meters from the crash site which was a Soviet production with Nr. 909-099510. It was launched by the Soviet Armed Forces' Southern Group of Forces formation in Hungary. At the 
collision $5 \mathrm{~m}^{3}$ hydrogen gas from the balloon exploded and damaged the aircraft leading to the crash. [4]

Many light and medium unmanned free balloons are launched with hydrogen still today. But a non-flammable gas (like helium) filled balloon can also lead to problems. The material of the balloon can cause damages to the engine, or the gas could cause problems at the combustion, which would lead to an emergency.

The radiosonde did not collide with the aircraft, but it could have. It could have been also absorbed by the jet engine, damaging it ending at least with an emergency landing. For visualization, an engine damage can be seen on Fig. 3. It has occurred by absorbing a mounting tool form ground.

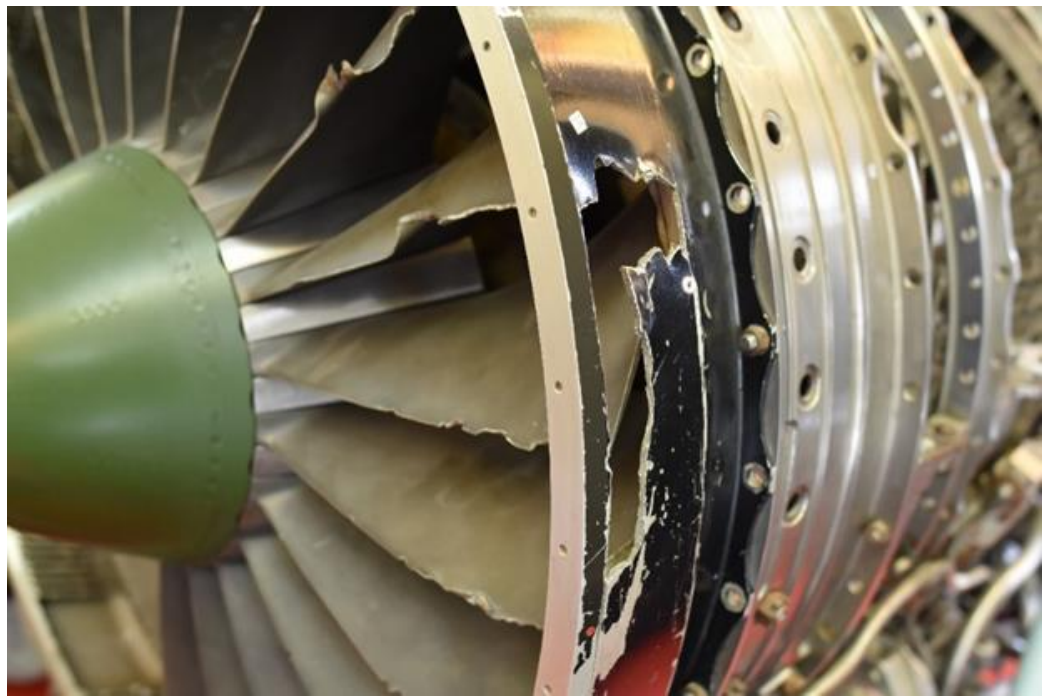

Figure 3. A damaged turbofan engine

This accident could recur also today by using the current air traffic control systems without tracking the light and medium unmanned free balloons. This is why it is necessary to develop a credible traceability.

\subsection{Helium balloons caused a private plane crash}

On 15th November 1993, a fatal plane crash happened near Brea (California, USA). The pilot flew a twin-engine cabin monoplane, a Piper PA-30 Twin Comanche at low altitude when it encountered a bundle of helium balloons. This was partially the cause of the vertical terrain impact. It can be also read in the 
National Transportation Safety Board's report, that the balloons came in contact with a hot object and that several of them were melted and bonded to each other. Notice that not just meteorological balloons can cause accidents. [5]

This accident can also recur, as small balloons without any tracking can also lead to accident.

\subsection{Using automatic dependent surveillance-broadcast technology}

As technical solutions evolve, the automatic dependent surveillance-broadcast (ADS-B) also gets smaller and lighter in size. The balloons analyzed here could use the same surveillance technology as proposed for unmanned aerial vehicle. [6] The usable devices are light and small ADS-B devices. For drones with a weight above 250 grams ADS-B usage was announced. It could be for example a ping $1090 \mathrm{i}$, that is advertised as the world's smallest and lightest automatic dependent surveillancebroadcast (ADS-B) solution for small unmanned aircraft systems. Its weight is about 26 grams. The main problem for a daily, common use would be currently the cost of these devices. This kind of systems cost about 2000 Euro. [7]

\section{Landing on streets, railway lines, populated areas}

Light and medium unmanned free balloons can also land on traffic routes of populated areas. Landing on places used by people can cause dangerous situation, lead to damages or even accidents.

\subsection{Landing on an expressway}

Meteorological balloons may also land on a street, country road or a motorway. A Vaisala RS41 radiosonde launched with Nr. R0920515 from Prague (in Czech Republic) landed on the S3 expressway near Wiadrów (in Poland) on 16th November 2019. On Fig. 4. the radiosonde can be seen on the edge of the road in the grass. [8] 


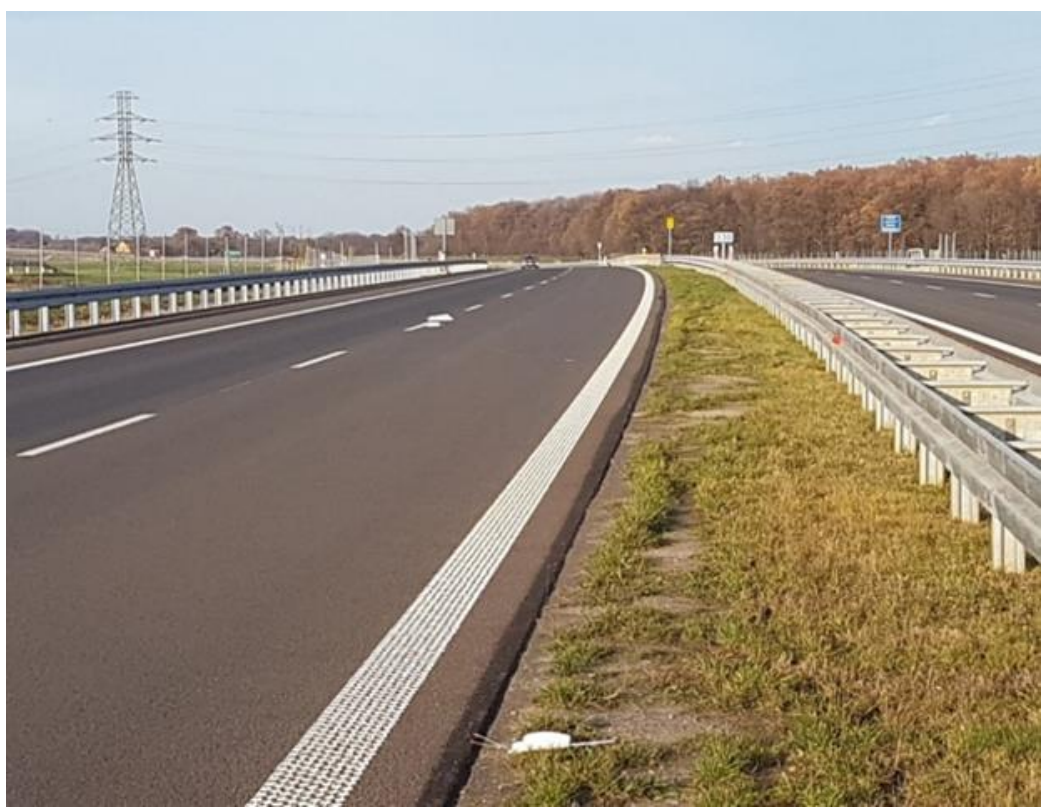

Figure 4. The radiosonde on $\mathrm{S} 3$ expressway [9]

In the background a white patch can be seen in the middle of the expressway which is most probably the balloon. A thin rope more precisely a string is connecting the two parts, which can be identified as a thin white line on the original photo. On a video showing the collecting of meteorological balloon it can be seen clearly that no parachute was used. [10] This meteorological balloon had a $13 \mathrm{~m} / \mathrm{s}$ descent rate in the last half minute of its flight. [8] This $13 \mathrm{~m} / \mathrm{s}$ measurement data also confirms that the descent rate without or with not functioning parachutes can be above $8-10 \mathrm{~m} / \mathrm{s}$. Radiosondes landing with this speed can cause significant damages.

Landing on expressway or motorway could lead to dangerous situations or damages. If a radiosonde with a speed of $13 \mathrm{~m} / \mathrm{s}$ and a car with a speed of $30.56 \mathrm{~m} / \mathrm{s}$ $(110 \mathrm{~km} / \mathrm{h})$ collided, the car would have a serious damage and the radiosonde would be most probably destroyed.

Germany has a dense federal controlled-access highway system (German word: Bundesautobahn; BAB) compared to many countries such as Hungary. It occurred, that a meteorological balloon has landed on one of this motorway tracks. As it landed on the outer lane of the track, the radiosonde was flattened most probably by a truck, by their withstanding, strong wheels. 


\subsection{Landing on railway track}

A light unmanned free balloon landed at a railway track near Svojšice village, in the Kolín District (in Czech Republic) on 2nd June 2015. The balloon was launched by N. Hegyi from Prague. As shown on Fig. 5. the track probably had not been used for some time.

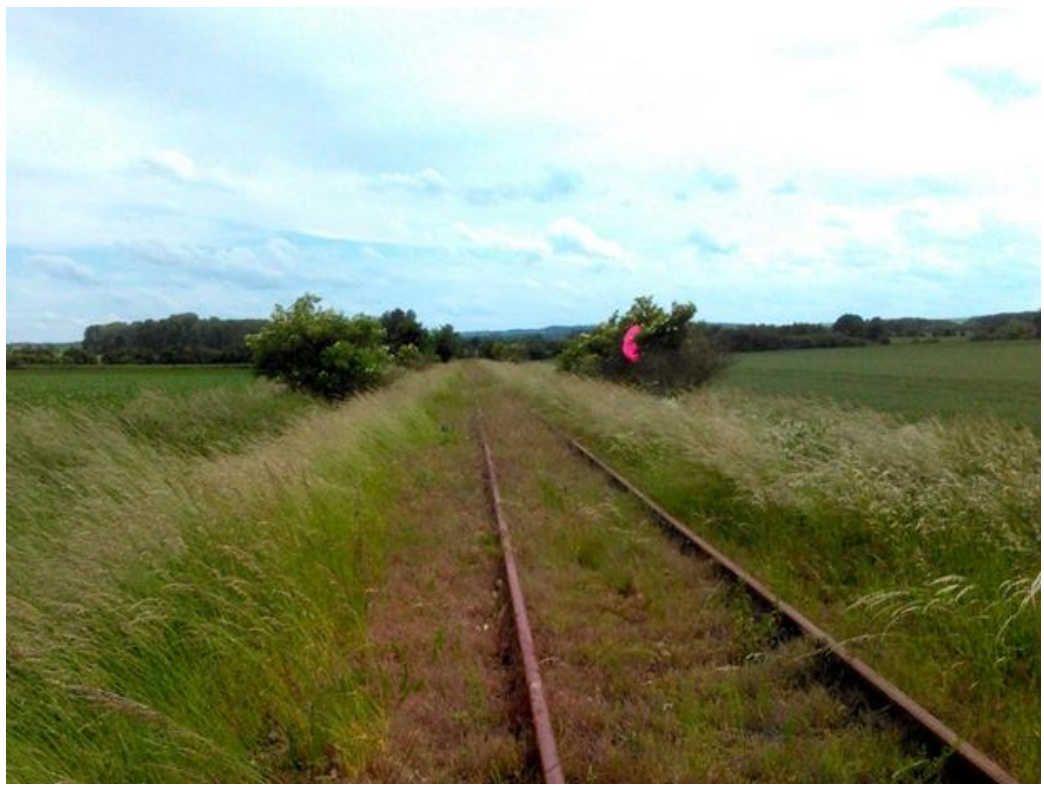

Figure 5. Light unmanned free balloon landed at railway track

It was a private use balloon, but to be clear many of them were developed and launched previously. The payload was structurally an expanded polystyrene (EPS) box inside a magenta colored "plastic bag" combined with yellow and orange colored reflective surfaces for a better visibility. The material of the bag was a light polyester waterproof fabric. It had multiple tracking devices and a photo camera installed inside. It had two GoPro Hero3 cameras in special protective cases and a partially flexible antenna for $144.800 \mathrm{MHz}$ Automatic Packet Reporting System tracking (APRS tracking) installed outside. The payload was connected to a magenta colored parachute made form the same material as the "bag" with a rope that required an impact force of less than $230 \mathrm{~N}$ to separate it from the balloon. This force is specified by Commission implementing regulation (EU) No 923/2012. [11] 


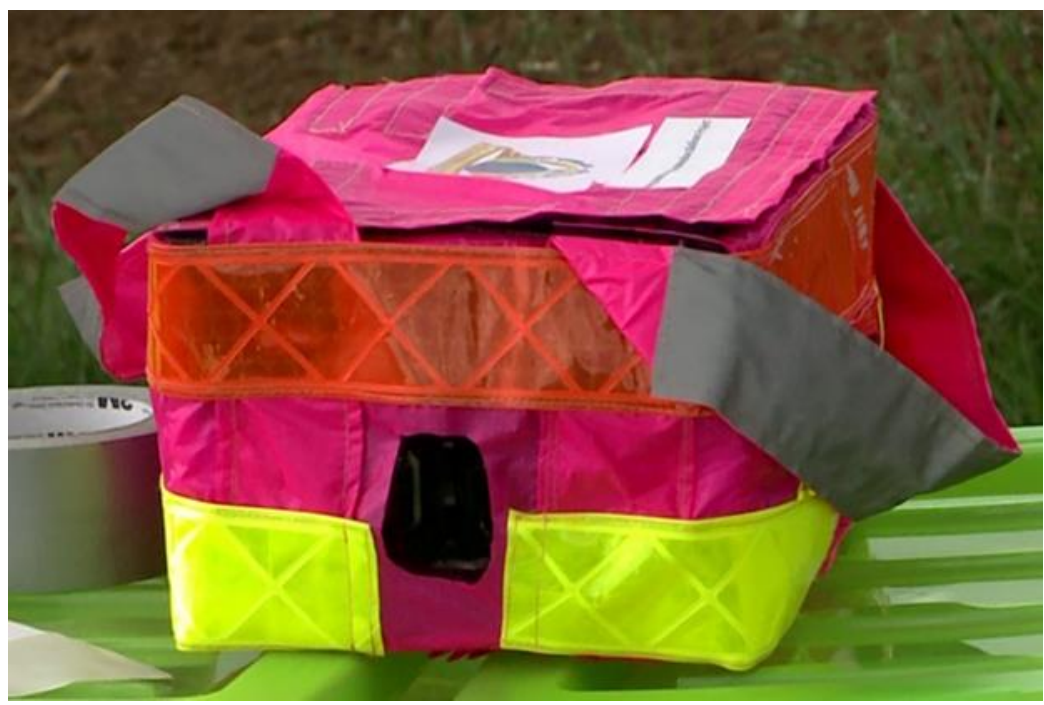

Figure 6. The payload

A locomotive and the balloon's parts could collide in many different situations. The payload can land on the track, it can hang on the rope from a tree (directly or by swinging), or it can be fitted with a rope having a greater tensile strength also. In case of the last option the locomotive could capture the balloon or the parachute, drag the payload with itself and cause damages. If a train had collided directly into the payload's harder parts, such as the specially protected GoPro cameras, they could have caused damages in the front lamps or ruptures in the windshield of the locomotive. This leads to the conclusion that the above-mentioned payloads need an outside layer for collision reduction.

\subsection{Landing on a parking car}

On 9th June 2011, the rear windshield of a parking Mazda Premacy car was broken by a Vaisala RS92-SGPW radiosonde as shown on Fig. 7. 


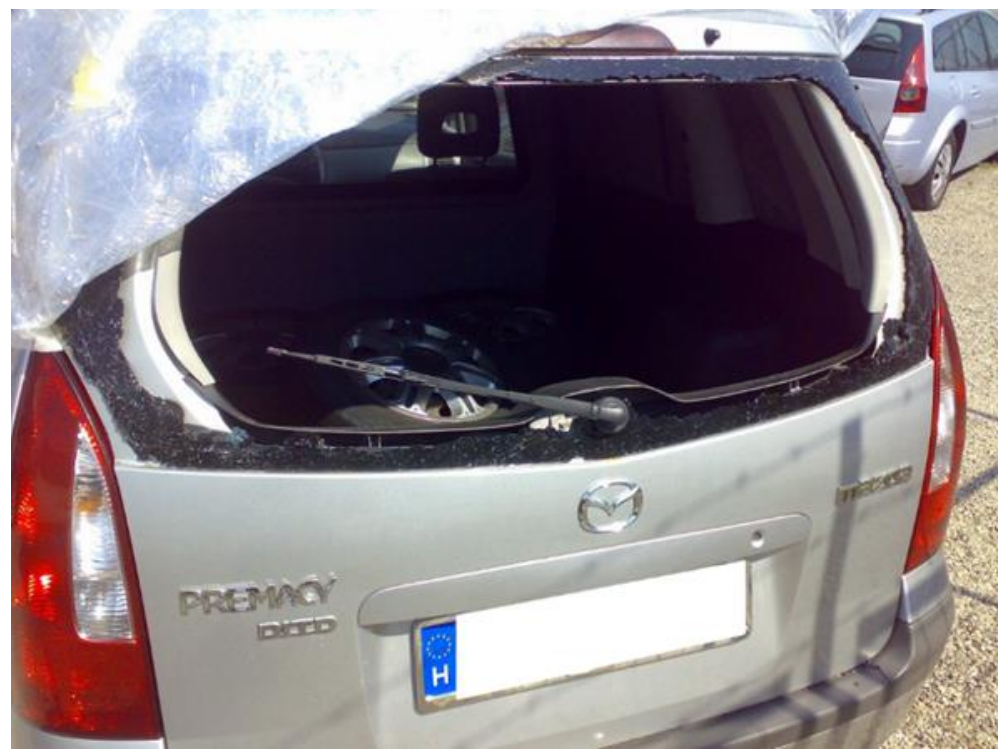

Figure 7. Broken car window [12]

The radiosonde was launched form Szeged Meteorological Observatory. The accident occurred 2,2-2,4 $\mathrm{km}$ from the launch site. The fractured radiosonde is shown on Fig. 8. The device fell apart. It was broken in many places. For better understanding, the structure of the Vaisala RS92 type radiosondes have a plastic shell, inside with an EPS layer for insulation, two small liquid filled pieces for heat containing purpose and the electronic parts.

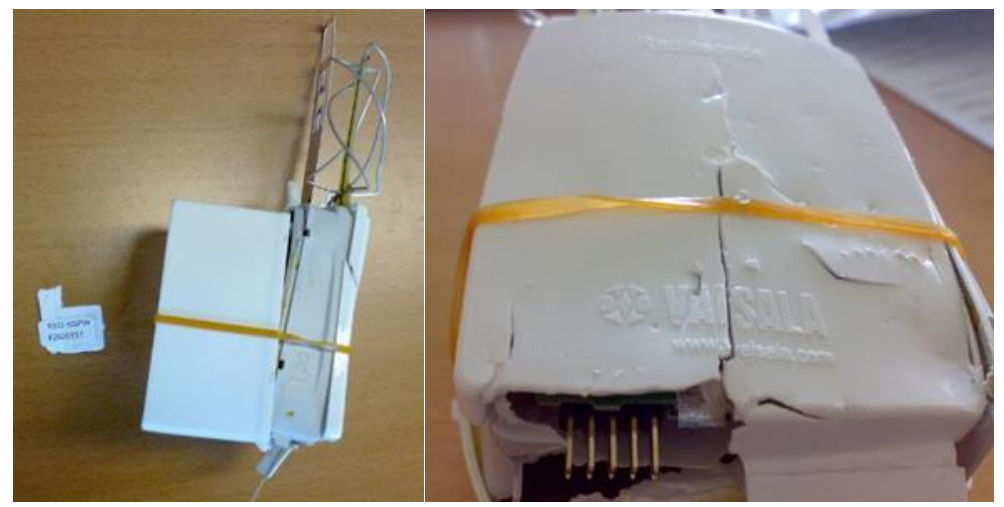

Figure 8. The broken radiosonde [12] 
Their weight varies by model. There are versions of $160 \mathrm{~g}$ with lithium batteries and 280-290 $\mathrm{g}$ with alkaline batteries as well. [13] This radiosonde was a heavier model. It had a $14-15 \mathrm{~m} / \mathrm{s}$ descent rate at landing. It had no parachute. It damaged a parking car. Thinking further, what could it have caused if it collided with a moving car? Although the Hungarian Meteorological Service replaced the usage of Vaisala RS92 radiosondes it needs to be stated that these models are still used by many meteorological institutes and services today.

\subsection{Landing on a building}

On 18th September 2014, an unmanned free balloon crashed into a building in Pánd village in Pest County (in Hungary). On Fig. 9. the crashed device can be seen, and it shows also the damage that has been caused to the building's roof tiles. It was a homemade balloon not complying with safety rules [14].

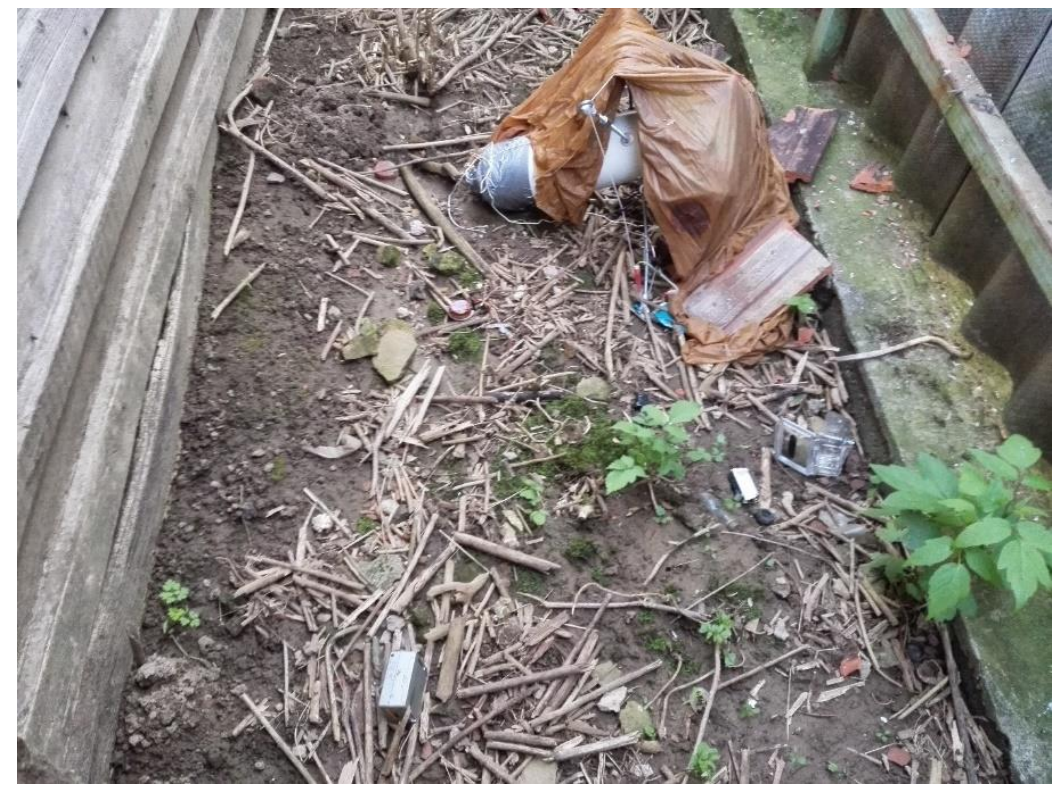

Figure 9. The sight of damage [14]

The brown colored "blanket" over the payload is the balloon part of the whole equipment. The payload's main part is made most probably from a white polyvinyl chloride (PVC) tube. As seen the payload is directly connected to the balloon without a parachute. There are metallic colored wire tensioners 4 times around the tube with a wire around it. The white wire is most probably loop antenna. It has a rectangular 
geometry. Near the payload (at the bottom right of the image) there are black and transparent parts of a GoPro Hero3 or Hero3+ waterproof housing. Next to this waterproof housing there is a $9 \mathrm{~V}$ battery mainly seen white as it reflects light. There is a red colored round piece on the image. It is most probably the timer part with a $9 \mathrm{~V}$ battery connector from a Soviet made Signal-402 pocket radio. Under the balloon the shape of a box can be seen. On footage not shown in this article, this black colored box is a part of the main body. So, the main body has a white colored PVC tube upper part and a black colored down part. At the bottom of this image a light grey box not far from the payload can be seen. From the photographs it is not clear what it is, but it is presumable a type of tracking device or a meteorological instrument. The "CE marking" can be seen, but not exactly in its standardized form.

It is not clear what size the payload is, but an approximation from relative sizes can be calculated. Also, an approximation for the mass of the parts can be calculated by searching their weight or their density. After doing this work the conclusion is that it should be at least $4-6.5 \mathrm{~kg}$. There is also equipment inside the payload which cannot be seen from outside. From this it can be concluded that the probe is heavier, than the previously specified weight. As written in the previously mentioned European regulation [11] if the balloon fits a few regulations with less than $4 \mathrm{~kg}$ weight payload it can be categorized still as a light unmanned free balloon, with a payload $4 \mathrm{~kg}$ or more, but less than $6 \mathrm{~kg}$ it is in the medium category. But with 6.5 $\mathrm{kg}$ it is definitely a heavy free unmanned balloon.

The type of the balloon used for the flight is not known. Its material is most probably latex. Most of the easily available latex balloons are not produced to lift $6,5 \mathrm{~kg}$ payloads for high altitude flights. But by calculating the needed filling volume for lifting the balloon with a heavy payload it can be proved, that there are products which would be usable for a flight lower than high altitudes. The conclusion is that the lifted weight of the analyzed payload may have exceeded $6.5 \mathrm{~kg}$.

At the crash site the balloon and the payload were connected, which means their weight could have varied in a wide range. Assuming extra weight of nonvisible parts inside the payload, and assuming the probable weight of the balloon itself the calculated mass could be $5-10 \mathrm{~kg}$.

On Fig. 9. the broken, fallen roof tiles can be seen. Most probably the metal made hard parts, such as the wire tensioners hit the roof most intense. Such hard parts may also have been installed if the payload was much lighter. This is one of the reasons to develop balloon payloads with a shock absorbing outer shell. It can be also concluded that homemade unmanned free balloons can be dangerous. 


\section{Summary of conclusions}

From this article it can be concluded that light and medium unmanned free balloons can lead to dangerous situations and accidents. Interviews confirm this conclusion. The above-mentioned aircraft balloon mid-air collision accidents show that the outcome of such an event can be fatal. The landing of a payload can also cause dangerous situations or even damages. Dangerous situations on expressways, highways were analyzed. Damages resulted by the impact of the probes were analyzed. They concluded, that the body of probes must be of a structure, material or shape that reduces the effects of the collision. We recommend that the light and medium unmanned free balloons be equipped with tracking devices, which can be useful for organizations providing air navigation services. This may reduce the number of aircraft proximity and mid-air collision events. The balloons analyzed here could use the same ADS-B technology for tracking as announced for drones above 250 grams. As a result, we could save human lives.

\section{References}

[1] NOAA, NOAA adopts technology to automate weather balloon launches, 7 . May 2018 [cited 2020-02-20]

URL https://www.noaa.gov/media-release/noaa-adoptstechnology-to-automate-weather-balloon-launches

[2] N. Hegyi, J. Jósvai, Unmanned Free Balloon Flight's Integration into Unmanned Aircraft System Traffic Management, Acta Technica Jaurinensis 12 (4) (2019) pp. 321-334.

doi: https://doi.org/10.14513/actatechjaur.v12.n4.522

[3] N. Hegyi, Safety issues for light and medium unmanned free balloons tracking, Repüléstudományi Közlemények 30 (2) (2018) pp. 217-224, in Hungarian.

[4] Military History Museum Military History Archives, Hungarian People's Army, National Air Defense Command: Investigation Report, Nr. 351/VII, 13th October 1970, Budapest

[5] U.S. Department of Transportation, Federal Aviation Administration, General information for NTSB report: LAX94FA047 [cited 2020-04-04] URL

https://www.asias.faa.gov/apex/f?p=100:17:::NO::AP_BRIEF_ RPT VAR:LAX94FA047 
[6] B. Syd Ali, Traffic management for drones flying in the city, International Journal of Critical Infrastructure Protection 26 (2019) 100310 doi: https://doi.org/10.1016/j.ijcip.2019.100310

[7] uAvionix; ping190i [cited 2020-04-08] URL https://uavionix.com/products/pinglo9o/

[8] Radiosondy [cited 2020-04-14]

URL

https://radiosondy. info/sonde_archive.php?sondenumber=R09 20515

[9] Photo by Tomasz Grzyb, Landing on S3 expressway; 16th November 2019, Poland

[10] Video by Thomasz Grzyb, Collecting of the radiosonde from Prague [cited 2020-04-14]

URL https://youtu.be/j441jRjv0zg

[11] EUR-Lex, Commission implementing regulation (EU) No 923/2012 [cited 2020-04-14]

URL https://eur-lex.europa.eu/legalcontent/EN/TXT/PDF/?uri=CELEX:32012R0923\&from=EN

[12] Hungarian Meteorological Service, 2011.

[13] Vaisala, Radiosonde RS92-SGP [cited 2020-05-04]

URL

https://www.vaisala.com/sites/default/files/documents/RS9 2SGP-Datasheet-B210358EN-F-LOW.pdf

[14] National Transport Authority, Aviation Authority's Aviation Safety Department, 2014. 